\title{
Influence of mental health and alcohol or other drug use risk on adolescent reported care received in primary care settings
}

\author{
Lisa S. Meredith ${ }^{1,2^{*}}$, Brett A. Ewing ${ }^{1}$, Bradley D. Stein ${ }^{3}$, William G. Shadel ${ }^{3}$, Stephanie Brooks Holliday ${ }^{1}$,
} Layla Parast ${ }^{1}$ and Elizabeth J. D'Amico ${ }^{1}$

\begin{abstract}
Background: To describe patterns of alcohol and other drug (AOD) use risk and adolescent reported primary care (PC) screening and intervention, and examine associations of AOD risk and mental health with reported care received.

Methods: We analyzed data from cross-sectional surveys collected from April 3, 2013 to November 24, 2015 from 1279 diverse adolescents ages 12-18 who reported visiting a doctor at least once in the past year. Key measures were AOD risk using the Personal Experience Screening Questionnaire; mental health using the 5-item Mental Health Inventory; binary measures of adolescent-reported screening and intervention.

Results: Half (49.2\%) of the adolescents reported past year AOD use. Of the 769 (60.1\%) of adolescents that reported being asked by a medical provider in PC about AOD use, only 37.2\% reported receiving screening/intervention. The odds of reported screening/intervention were significantly higher for adolescents with higher AOD risk and lower mental health scores.
\end{abstract}

Conclusions: Adolescents at risk for AOD use and poor mental health are most likely to benefit from brief intervention. These findings suggest that strategies are needed to facilitate medical providers identification of need for counseling of both AOD and mental health care for at risk youth.

Trials registration: clinicaltrials.gov, Identifier: NCT01797835, March 2013.

Keywords: Screening and brief intervention, Adolescents, Primary care

\section{Background}

Rates of alcohol and other drug use (AOD) continue to be high [1] and adolescent AOD use is associated with significant health and social consequences [2-8]. AOD use also increases risk of having an AOD disorder as an adult [9], and is associated with high economic and societal costs $[10,11]$. Because most adolescents seek care in a primary care (PC) setting at least once a year [12-14], early identification or treatment by PC clinic staff is a promising way to prevent or ameliorate AOD among adolescents [15], and multiple guidelines recommend

\footnotetext{
* Correspondence: lisa_meredith@rand.org

'RAND Corporation, 1776 Main Street, Santa Monica, CA 90407-2138, USA ${ }^{2}$ VA HSR\&D Center for the Study of Healthcare Innovation, Implementation, and Policy, California, Los Angeles, USA

Full list of author information is available at the end of the article
}

such screening [16-18]. However, rates of screening and intervention for $\mathrm{AOD}$ in $\mathrm{PC}$ are low for adolescents [19-22]. Some of the reasons for low AOD screening rates are that providers are unsure of the importance of prevention and approval of alcohol screening [23], limited organizational support, lack of training, discomfort [24], and limited opportunity [25]. Other obstacles include lower provider perceived alcohol-management skills, and lower provider self-efficacy $[23,25]$.

National surveys on adolescent AOD use and mental health problems consistently find overlap between these disorders [26-28]. Adolescent reports of AOD use and mental health symptoms also co-occur [29]. To our knowledge, the potential additive or interactive effect of having poor mental health and risky AOD use on PC screening/intervention has not been examined. We 
address this gap in the literature, by examining the association between AOD use and adolescent-reported screening/intervention by medical providers in PC settings. Our research questions were: 1) Are adolescents with greater risk for AOD more likely to report being screened by a medical provider in PC for AOD use and followed up with intervention compared to adolescents with less risk for AOD use? 2) Does having poorer mental health in addition to higher AOD risk increase the odds that adolescents will report receiving an intervention in a PC setting to address AOD risk?

\section{Methods}

\section{Study settings}

The study sample was recruited from PC clinics providing care predominantly for ethnically and racially diverse and underserved adolescents in Pittsburgh, PA (3 clinics) and Los Angeles, CA (1 clinic). These sites offer longitudinal, continuity-based care and episode-based urgent care to their patients. Clinics in both areas have a large percentage of minority patients and low-income patients who are uninsured or underinsured (i.e., insured through Medicare and/or Medicaid).

\section{Participants and procedures}

Every adolescent between age 12 and 18 in the clinic waiting rooms with a scheduled appointment was asked to be part of the project. For interested adolescents, we obtained parental consent and assent (if under 18) or consent if 18 . Youth were screened by project staff using the National Institute of Alcohol and Alcohol Abuse (NIAAA) screening guide, completed a survey via the web from April 2013 to November 2015, and were paid $\$ 25$. We obtained a certificate of confidentiality; the Institutional Review Boards and the clinics approved procedures.

Approximately 3309 adolescents were approached to participate; $27 \%(n=892)$ were ineligible because they were not 12-18 years old, not proficient in English, were not at the clinic for their own appointment, or were disabled, and $18.5 \%(n=614)$ refused to participate (mostly because of adolescents' concerns that their parents would learn they were at the clinic for a family planning appointment or because of time constraints). After exclusions, 1803 adolescents enrolled or consented for study staff to contact them. Of the 1803 adolescents, 230 did not complete the baseline survey within the field period or had inaccurate contact information. This yielded a final sample of 1573 adolescents. The average age was $15.5 ; 42.5 \%$ were male; $51.4 \%$ were Hispanic, $26.7 \%$ black, $14.8 \%$ white, and $7.2 \%$ multiethnic or other. We focus on 1279 adolescents who reported visiting the doctor at least once in the past year and also had usable information to allow categorization into an AOD risk category.

\section{Measures}

We used items from a longitudinal national household survey to assess five main outcomes of self-reports of screening and intervention [30, 31]. Adolescents were asked, "In the past 12 months, did any medical provider (e.g., primary care physician, general internist, nurse, physician assistant, chiropractor, or health clinic): 1) ask about use of alcohol or drugs (screening), 2) suggest cutting down or stopping use of alcohol or drugs (education/advice intervention), 3) suggest seeing a specialist or special program for emotions, mental health, or alcohol or drug use (referral intervention), or 4) provide counseling about emotions, mental health, alcohol or drug use for at least 5 minutes (counseling intervention)." We created binary indicators for each of these outcomes plus a fifth indicator for receipt of screening plus at least one type of intervention.

We assessed AOD risk using the 18-item Problem Severity Scale of the Personal Experience Screening Questionnaire (PESQ-PS) [32] that is reliable and valid for use in a general adolescent population. The PESQ-PS consists of eight items about AOD use in different contexts, nine items about behaviors and consequences of AOD use, and a single item about selling drugs to pay for AOD use. Items were rated on a 4-point frequency scale (never, once or twice, sometimes, or often). We used validated cutpoints on the summed score (ranging from 18 to 72; $\alpha=$ $0.93)$ to stratify adolescents into risk groups. Low risk or green flag suggests no further assessment or referral is recommended because the individual has no problem with AOD use. Medium risk or yellow flag suggests that the individual has a mild or moderate problem with AOD use requiring brief intervention. High risk or red flag suggests abusive or dependent use of AOD requiring comprehensive evaluation to confirm severity of the problem with likely referral for substance abuse treatment. Cut-points by gender and age range were $>23-24$ for yellow flag and $>30$ 35 for red flag.

We measured mental health using the well-validated 5item Mental Health Inventory (MHI-5) [33]. Respondents indicated frequency for five feelings during the past month on a 1-6 scale (all of the time to none of the time). Item content included feeling nervous, calm and peaceful, downhearted and blue, happy, and down in the dumps. Relevant items were reversed so that a higher total score (transformed to range from 0 to $100 ; \alpha=0.73$ ) indicated better mental health.

We controlled for adolescent age, gender, indicators of race/ethnicity, and mother's education (less than college vs. at least some college). We imputed incomplete data 
for mother's education using an ordinal logistic regression model with race/ethnicity, city, and living in a two-parent household [34, 35].

\section{Analysis}

We first describe sample characteristics, patterns of, and rates of screening and intervention overall and by risk AOD groups by the PESQ-PS. We use multivariable logistic regression to estimate odds of receiving screening and each type of intervention as a function of AOD use risk and mental health, controlling for demographic characteristics (age, gender, race, and mother's education). To understand the independent effect of AOD risk, the effect of AOD risk after controlling for mental health, and the interactive effect of AOD risk and mental health, we ran three sets of models: (1) including only the main effect for AOD risk groups without the MHI-5, (2) adding the main effect for MHI-5, and (3) adding the interaction between AOD risk and MHI-5. We conducted analyses using standard statistical software (SAS 9.3). We adjusted for clustering of adolescents within clinics using fixed effects for clinics.

\section{Results}

\section{Sample characteristics}

This analysis sample $(n=1279)$ was similar to the full enrolled sample $(n=1573)$ (Table 1$)$ : average age of

Table 1 Adolescent Sample Characteristics by AOD Risk Groups on the PESQ

\begin{tabular}{|c|c|c|c|c|}
\hline & \multirow{2}{*}{$\begin{array}{l}\text { Full Sample } \\
(\mathrm{n}=1279)\end{array}$} & \multicolumn{3}{|c|}{ PESQ Risk Group } \\
\hline & & $\begin{array}{l}\text { Green } \\
\text { Flag } \\
(n=886)\end{array}$ & $\begin{array}{l}\text { Yellow } \\
\text { Flag } \\
(n=195)\end{array}$ & $\begin{array}{l}\text { Red } \\
\text { Flag } \\
(n=221)\end{array}$ \\
\hline $\mathrm{Age}^{* *}$ & $15.6(0.2)$ & $15.2(0.2)$ & $16.3(0.1)$ & $\begin{array}{l}16.7 \\
(0.1)\end{array}$ \\
\hline \multicolumn{5}{|l|}{ Gender*** } \\
\hline Male & 40.4 & 42.1 & 40.9 & 33.2 \\
\hline Female & 59.6 & 57.9 & 59.1 & 66.8 \\
\hline \multicolumn{5}{|l|}{$\operatorname{Race}^{* * *}$} \\
\hline White & 15.0 & 14.8 & 16.6 & 14.5 \\
\hline Black & 26.3 & 28.5 & 24.9 & 19.1 \\
\hline Hispanic & 52.0 & 48.8 & 55.4 & 61.4 \\
\hline Multiethnic/Other & 6.6 & 7.9 & 3.1 & 5.0 \\
\hline \multicolumn{5}{|l|}{ Mother's Education } \\
\hline Less than college & 67.1 & 65.2 & 67.9 & 73.4 \\
\hline $\begin{array}{l}\text { At least some } \\
\text { college }\end{array}$ & 32.9 & 34.8 & 32.1 & 26.6 \\
\hline MHI-5 Score $(0-100)^{* * *}$ & $68.5(1.0)$ & $69.9(0.7)$ & $70.3(2.0)$ & $\begin{array}{l}61.5 \\
(1.0)\end{array}$ \\
\hline
\end{tabular}

$A O D$ Alcohol or drug use, PESQ Personal Experience Screening Questionnaire; 228 cases were imputed for missing data on mother's education; Analyses are adjusted for clustering within clinic; ${ }^{* *} \mathrm{p}<.01$; ${ }^{* * *} \mathrm{p}<.001$
15.6 years, 40.4\% male, 26.3\% Black, 52.0\% Hispanic, and $6.6 \%$ multiethnic. Most mothers (67.1\%) had no college education. The average score on the MHI-5 was 68.5. All characteristics differed significantly across PESQ-PS risk groups except for mothers' education. Adolescents at highest risk (red flag) were significantly older $(p<.01)$, more likely to be female $(p<.001)$, more likely to be Hispanic $(\mathrm{p}<.001)$, and reported lower mental health scores $(\mathrm{p}<.001)$.

\section{Patterns of screening and intervention}

Figure 1 illustrates the flow of screening and interventions as reported by the 1279 adolescents who answered the question about care received (screening and intervention) in a past year doctor visit. Of the 769 adolescents who reported being asked about AOD use (e.g., any reported AOD screening), 72.8\% $(n=560)$ reported being screened for AOD use by the doctor but received no further intervention, and 209 reported being screened and at least one type of intervention. Of those 769 adolescents, only $13.1 \%$ $(n=101)$ reported being asked to cut down or stop using AOD, $11.8 \%(n=91)$ reported being referred to a mental health specialist or substance use program, and $17.7 \%(n$ =136) reported receiving counseling for at least five minutes about mental health or AOD. Limited numbers of adolescents reported receiving multiple interventions, with only 27 receiving all three interventions. Almost $40 \%$ of adolescents reported that they were not screened about AOD use, and the 510 adolescents, the majority received no intervention $85.1 \%(n=434)$. But, $7.2 \%(n=37)$ of unscreened adolescents reported being asked to cut down or stop using AOD, 4.9\% $(n=25)$ reported being referred to a mental health specialist or substance use program, and $8.6 \%(n=44)$ reported receiving counseling for at least five minutes about mental health or AOD.

\section{Rates of screening and intervention}

Rates of screening and intervention as reported by adolescents were significantly higher with increased risk (omnibus test, $p<.001$ for all) (Fig. 2). Adolescents in the red flag group were $18 \%$ more likely to be screened for AOD use compared with the green flag group $(p<$ 0.001 ). For intervention, $25 \%$ more red flag adolescents reported being advised to cut down or stop use than were green flag adolescents $(p=0.003)$. This difference was $12 \%$ more for referral $(p=0.016)$ and $18 \%$ more for counseling $(p=0.002)$. Red flag adolescents were also $29 \%$ more likely to report screening plus intervention relative to green flag adolescents $(\mathrm{p}=0.002)$.

\section{Associations between AOD risk and mental health with screening and intervention}

Table 2 shows the results for multivariable logistic regression models estimating the likelihood of adolescent 


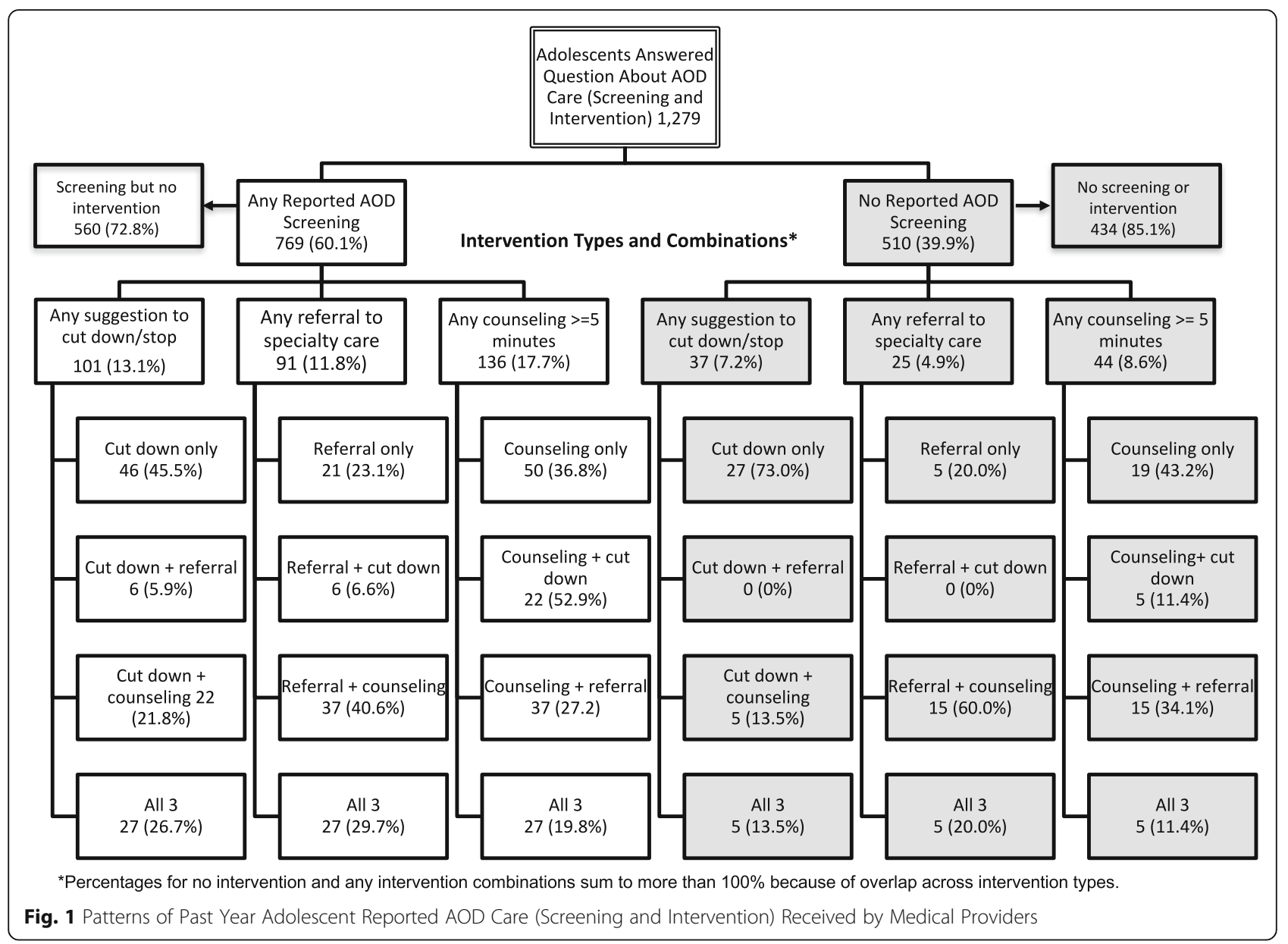

reported screening and intervention received from medical providers after adjusting for clustering within clinic and demographic characteristics. Models include the main effects for both MHI-5 and AOD risk (without the interaction). Better mental health was not significantly associated with adolescents reporting being asked about AOD use or advice to cut down or stop using AOD, but was significantly associated with a slightly lower likelihood of reporting being referred, counseled, or getting screened and receiving any type of

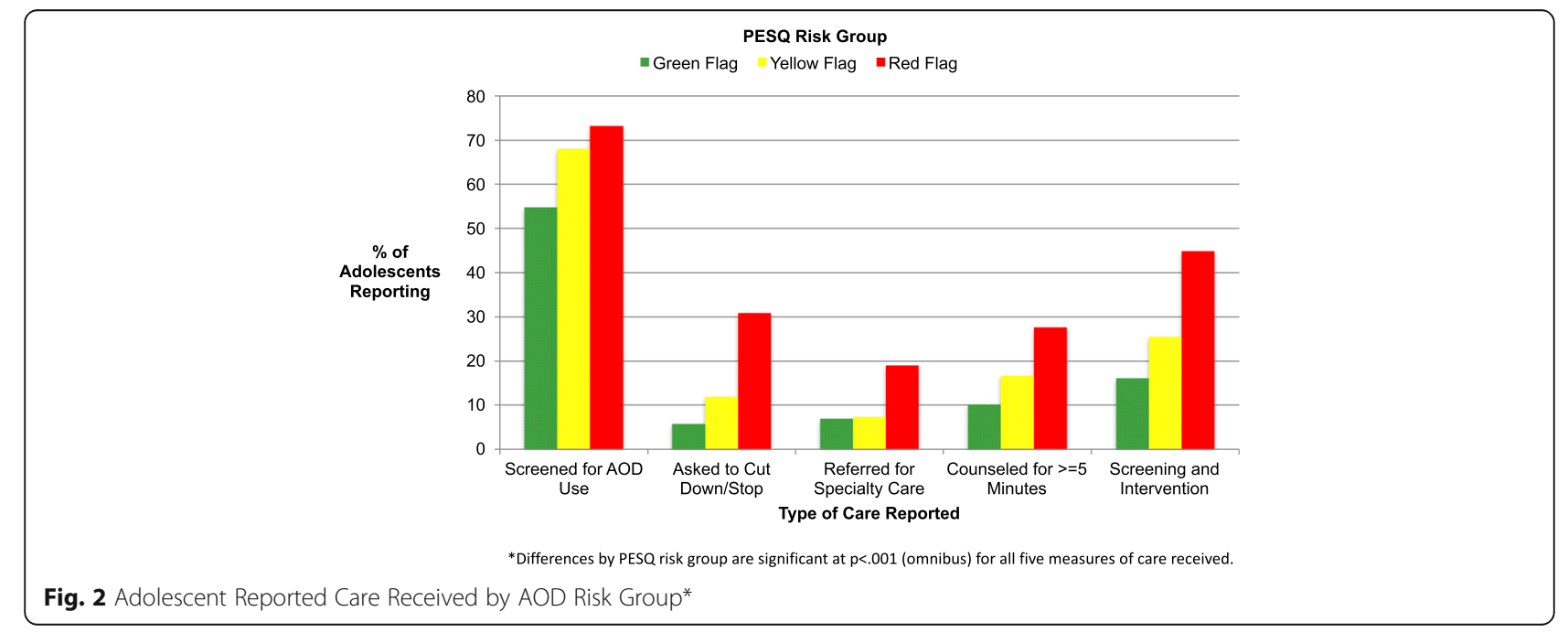


Table 2 Odds Ratios for Adolescent Reported Screening or Intervention Received by Medical Providers in Primary Care

\begin{tabular}{|c|c|c|c|c|c|}
\hline \multirow[b]{3}{*}{ Independent Variable } & \multicolumn{5}{|c|}{ Screening or Intervention (Dependent Variable) } \\
\hline & $\begin{array}{l}\text { Asked about } \\
\text { AOD use }\end{array}$ & $\begin{array}{l}\text { Suggested cutting down } \\
\text { or stopping AOD use }\end{array}$ & $\begin{array}{l}\text { Referred for } \\
\text { specialty care }\end{array}$ & $\begin{array}{l}\text { Counseled for } \\
>=5 \mathrm{~min}\end{array}$ & $\begin{array}{l}\text { Asked and provided } \\
\text { any treatment }\end{array}$ \\
\hline & OR $[95 \% \mathrm{Cl}]$ & OR $[95 \% \mathrm{Cl}]$ & OR $[95 \% \mathrm{Cl}]$ & OR $[95 \% \mathrm{Cl}]$ & OR $[95 \% \mathrm{Cl}]$ \\
\hline MHI-5 Score (0-100) & $1.01[1.00-1.01]$ & $1.01[1.00-1.02]$ & $\begin{array}{l}0.97 \\
{[0.96-0.98]^{* * *}}\end{array}$ & $\begin{array}{l}0.97 \\
{[0.97-0.98]^{* * *}}\end{array}$ & $0.98[0.97-0.99]^{* * *}$ \\
\hline \multicolumn{6}{|l|}{ PESQ Risk Flags } \\
\hline Red (vs. Green) & $1.69[1.19-2.40]^{* *}$ & $8.89[5.59-14.14]^{* * *}$ & $\begin{array}{l}2.80 \\
{[1.73-4.54]^{* * *}}\end{array}$ & $\begin{array}{l}3.48 \\
{[2.29-5.30]^{* * *}}\end{array}$ & $4.44[3.11-6.36]^{* * *}$ \\
\hline Yellow (vs. Green) & $1.36[0.96-1.92]$ & $2.37[1.37-4.09]^{* *}$ & $1.14[0.61-2.14]$ & $\begin{array}{l}2.15 \\
{[1.35-3.42]^{* * *}}\end{array}$ & $2.03[1.37-3.01]^{* * *}$ \\
\hline Age & $\begin{array}{l}1.25 \\
{[1.17-1.34]^{* * *}}\end{array}$ & $0.98[0.88-1.11]$ & $0.96[0.85-1.08]$ & $0.88[0.80-0.97]^{*}$ & $0.93[0.85-1.01]$ \\
\hline \multicolumn{6}{|l|}{ Gender } \\
\hline Female (vs. Male) & $1.19[0.93-1.52]$ & $0.61[0.41-0.91]^{*}$ & $0.81[0.53-1.25]$ & $0.93[0.65-1.33]$ & $0.81[0.60-1.08]$ \\
\hline \multicolumn{6}{|l|}{ Race } \\
\hline Black (vs. White) & $\begin{array}{l}0.42 \\
{[0.27-0.66]^{* * *}}\end{array}$ & $1.03[0.51-2.08]$ & $1.00[0.50-1.99]$ & $0.91[0.50-1.68]$ & $0.80[0.48-1.33]$ \\
\hline Hispanic (vs. White) & $\begin{array}{l}0.40 \\
{[0.26-0.64]^{* * *}}\end{array}$ & $0.98[0.49-1.97]$ & $1.17[0.58-2.33]$ & $1.12[0.62-2.01]$ & $0.93[0.57-1.54]$ \\
\hline Multi/Other (vs. White) & $0.56[0.31-0.99]^{*}$ & $1.05[0.41-2.69]$ & $0.88[0.32-2.38]$ & $1.46[0.69-3.10]$ & $1.12[0.58-2.13]$ \\
\hline \multicolumn{6}{|l|}{ Mother's Education } \\
\hline At least some college (vs. less than college) & $1.07[0.81-1.41]$ & $0.93[0.59-1.45]$ & $1.10[0.69-1.76]$ & $1.31[0.89-1.93]$ & $1.22[0.88-1.69]$ \\
\hline \multicolumn{6}{|l|}{ Clinic } \\
\hline Clinic A (vs. Clinic D) & $0.80[0.52-1.26]$ & $1.53[0.75-3.12]$ & $1.45[0.68-3.10]$ & $1.25[0.67-2.32]$ & $1.36[0.81-2.30]$ \\
\hline Clinic B (vs. Clinic D) & $0.66[0.43-1.02]$ & $1.08[0.53-2.20]$ & $1.86[0.92-3.76]$ & $1.36[0.76-2.44]$ & $1.26[0.76-2.08]$ \\
\hline Clinic C (vs. Clinic D) & $0.87[0.54-1.40]$ & $0.98[0.45-2.15]$ & $1.79[0.87-3.69]$ & $0.79[0.41-1.55]$ & $0.98[0.56-1.70]$ \\
\hline
\end{tabular}

228 cases were imputed for missing data on mother's education. $\mathrm{OR}=$ odds ratio; $\mathrm{Cl}=$ confidence interval; $\mathrm{AOD}=$ alcohol or drug use; $\mathrm{PESQ}=\mathrm{Personal}$ Experience Screening Questionnaire; Analyses are adjusted for clustering within clinic; ${ }^{*} \mathrm{p}<.05 ;{ }^{* *} \mathrm{p}<.01 ;{ }^{* * *} \mathrm{p}<.001$

intervention (all OR $=0.97-0.98, p<.001$ ). Higher AOD risk was significantly associated with increased likelihood of receiving screening and all types of intervention for red flag vs. green flag (all $\mathrm{p}<.001)$ and with suggesting cutting down $(p<.01)$, counseling $(\mathrm{p}<.001)$, and screening plus any intervention $(\mathrm{p}<.001)$ for yellow flag vs. green flag. Compared to the green flag group, adolescents in the red flag group were 1.7 times more likely to report being screened, 8.9 times more likely to report being advised to cut down or stop AOD use, 2.8 times more likely to be referred, 3.5 times more likely to be counseled for at least five minutes, and 4.4 times more likely to have been both screened and received an intervention.

Compared with the set of models that excluded the main effect of MHI-5 (not shown), including MHI-5 in the model increased the associations between AOD risk and AOD screening $(\triangle \mathrm{OR}=0.06)$ and advice to cutdown or stop for red flag $(\Delta \mathrm{OR}=0.43)$, but decreased the associations for referral $(\Delta \mathrm{OR}=-0.75)$, brief counseling $(\Delta \mathrm{OR}=-0.67)$, and screening plus any intervention $(\Delta \mathrm{OR}=-0.56)$ for red flag. However, the pattern of significance for the AOD risk associations was generally similar across the model specifications.

In terms of demographic associations with screening or intervention, being older was associated with higher odds of being screened ( $\mathrm{OR}=1.25, p<.001)$ but lower odds of being counseled ( $\mathrm{OR}=0.88, p<.05)$. Black (OR $=0.42, \mathrm{p}<.001)$, Hispanic $(\mathrm{OR}=0.40, p<0.001)$ and Multiracial or other non-white race/ethnicity $(\mathrm{OR}=0.56$, $p<.01)$ adolescents had lower odds of being screened. We found no significant interactions between AOD risk and MHI-5 (not shown) for the set of models that added the interaction terms.

\section{Discussion}

Adolescent AOD risk is a continuing concern. The PC setting provides an optimal opportunity for querying adolescents about risk behavior, including AOD use. This study contributes new information to the literature on adolescent AOD screening by examining both AOD use and mental health status together. Another contribution of this study is its examination of a large and 
diverse sample of underserved adolescents to understand the extent to which AOD risk and mental health influence the care that adolescents receive. Fully $85 \%$ of the sample is from diverse racial and ethnic backgrounds and unlike earlier studies includes adolescents from the full age range (12-18 year olds) incorporating those under age 16.

We found that consistent with previous research [19, $21,22]$, overall rates of screening and intervention for adolescent AOD use were low. Specifically, less than two thirds reported being screened for use, and only a third of those at risk for AOD use (yellow or red flag on the PESQ) who were screened for AOD use reported receiving some type of intervention.

We also found that the odds of being screened or receiving brief intervention for AOD use increased for adolescents who were at highest risk. This suggests that medical providers in PC are identifying and addressing those who are more dependent on substances. We did not find, however, that having both higher risk of AOD use and poorer mental health increased the odds of receiving screening and intervention. Our models that included the MHI-5 intensified the associations between AOD risk for screening and advice outcome measures but attenuated the associations for referral, counseling, or screening plus an intervention. This suggests that medical providers are identifying risky AOD use independent of mental health problems and that poorer mental health may also be a trigger for more screening and advice about AOD use. Given the high rates of comorbidity between AOD use and mental health among adolescents, adolescents identified as high-risk for both problems may benefit from referral to integrated models of care.

We also observed significant associations between demographic characteristics and reported care. Older adolescents were more likely to report being screened, but less likely to report being counseled which could be explained by the higher rates of use among older adolescents. Adolescents from racial/ethnic minority groups were less likely to report being screened. This suggests potential disparities in care across race/ethnicity.

This study has several strengths. It is the first to examine the likelihood of adolescents' receipt of care from a medical provider for AOD risk for varying levels of risk with a large and diverse population, as well as examining the additive effect of having poor mental health on reported care. Nevertheless, findings must be interpreted with a few caveats. The outcome measures of AOD screening and intervention are based on adolescent selfreports, which could be biased [36]. Further, we relied on a one year retrospective reporting period, which, given its length, could limit accuracy. For example, cognitive factors such as poor recall or comprehension [37] could compromise accuracy of responses and situational factors including social desirability [38], and perceived lack of confidentiality could also lead to underreporting of risky behavior. However, we designed clinic recruitment procedures for maximum confidentiality by securing private space to conduct assessments for study eligibility. Further, surveys were web-based self-reports that could be completed in private areas. We also included a fictitious drug in the survey and very few respondents reported taking it (only 10 of 1573 adolescents), which suggests that reporting was not necessarily biased [39] and estimates of AOD use in our sample match national survey norms [40]. Finally, this U.S. based study may not generalize to other areas in the U.S. or to other countries with different healthcare systems.

We also cannot determine whether the large number of adolescents who did not report receiving any form of intervention was due to a positive screening but no care or because youth were screened and deemed not to be at risk. Despite this uncertainty, we know that adolescents in the red flag group, who were current AOD users, reported not being screened for use e.g., less than $100 \%$ of those in need were screened. This suggests that PC is missing opportunities to identify adolescents at risk and intervene with them early in their lifespan to prevent future consequences of prolonged AOD use. Finally, because of the way in which the screening and intervention question was worded, we cannot separate out counseling for AOD use from counseling for mental health problems. Future research is needed to disentangle counseling for AOD use and from mental health counseling.

With continuing high prevalence of AOD use among adolescents, strategies for facilitating the opportunity to intervene and educate adolescents in primary care about AOD use may be warranted. These strategies should address some of the barriers to screening and intervention by providing organizational support and training [24] so that PC can more easily integrate screening into the adolescent's appointment and ultimately prevent or delay AOD use into adulthood when it is less risky. Such efforts, however, should acknowledge that there is inconclusive evidence for screening's effectiveness in reducing substance use among adolescents [41], and also recognize that PC providers may screen; however, competing time demands [42, 43] and/or limited training [23] may prevent them from being able to deliver effective interventions.

Although less accurate than validated intervieweradministered diagnostic instruments, single item screening questions (SISQs) are a promising approach to screening for risky health behaviors in PC settings because they are both practical and feasible [44-46]. SISQs are 
sufficiently brief for incorporation into busy practice settings, are less likely to be biased by social desirability, and also may facilitate conversations in a less stigmatized manner $[47,48]$. Recently, a study validated the use of a selfadministered SISQ for AOD use on a tablet for adult primary care patients [49]. Tablet administration decreases provider burden and may lessen stigma for patients compared with responding to provider questions directly. Such an approach could be broadly incorporated into primary care practice and may be adaptable for use with adolescents. Moreover, such a screening approach could decrease discomfort associated with discussing a sensitive topic and would also be time efficient.

However, screening alone is not enough. It must be paired with approaches for delivering brief interventions in the primary care setting. Consistent with Sterling et al. (2012) [24] implementing clinical practices and policies to address the barriers to intervention are needed. These include restructuring practice to allow for extra time needed for encounters with at-risk adolescents, such as flexible scheduling, reimbursement for longer visits with at-risk patients, or advance visit self-screening. Other facilitators to screening and intervention may include additional training for medical providers to increase comfort with addressing AOD use (e.g., de-stigmatize) [50, 51], as well as addressing concerns regarding patient confidentiality and adverse consequences of documenting AOD use in the medical record. Intervening in as little as $15 \mathrm{~min}$ can lead to positive behavior change [52]. Additionally, future research should examine the relative effectiveness of the screening, brief intervention, and referral to treatment model [53, 54] for risky AOD use to facilitate provider competency for delivering such care for adolescents in PC settings. Finally, given the high rates of comorbidity between AOD use and mental health issues, strategies are needed to facilitate medical providers' understanding of the importance of potential identifying the need for counseling of both AOD and mental health care for at risk youth.

\section{Conclusion}

Risky AOD use by adolescents remains a concern, particularly among adolescents with poor mental health functioning. Although there are barriers to screening [23-26], many providers are aware of the important role of screening for both of these problems so that adolescents may be referred to needed services. While screening rates were low in this large and diverse sample of adolescents, those at highest risk were significantly more likely to be screened and receive intervention. Findings highlight the continued need to decrease barriers in PC settings for screening and intervention with adolescents at risk for AOD use. Older adolescents were more likely to be screened but not to receive intervention, and were actually less likely to receive counseling. Adolescents from minority groups were significantly less likely to be screened than white adolescents but race/ethnicity was not associated with receipt of any type of intervention.

These findings underscore the importance of identifying practical, effective, and cost-effective strategies for addressing AOD risk among adolescents in PC settings. Further, to ensure that adolescents who screen positive for AOD use receive some sort of intervention and further assessment of mental health status, practice-based strategies that support the extra time needed for at-risk youth through flexible scheduling and reimbursement for expanded encounter durations are needed. Finally, strategies for facilitating PC provider competency including training about how to screen in a sensitive manner that feels comfortable and addresses issues of stigma, perceived confidentiality, and potential adverse consequences of patient disclosure are needed.

\section{Abbreviations}

AOD: Alcohol and Other Drug use; MHI-5: 5-Item Mental Health Inventory; NIAAA: National Institute on Alcohol Abuse and Alcoholism; OR: Odds Ratio; PESQ-PS: Personal Experience Screening Questionnaire-Problem Severity Scale; SAS 9.3: Statistical Analysis Software version 0.3; SISQ: Single Item Screening Questions

\section{Acknowledgements \\ The authors wish to thank the clinics that participated and supported this project. We would also like to thank Kirsten Becker and Jennifer Parker for overseeing the survey administrations, Rachana Saleem for helping with statistical programming, and Rosie Velasquez for help with manuscript formatting.}

\section{Funding}

Work on this article was supported by a grant from the National Institute of Alcohol Abuse and Alcoholism (R01AA021786) to Elizabeth D'Amico.

\section{Availability of data and materials}

The data that support the findings of this study are available from the corresponding author upon reasonable request.

\section{Authors' contributions}

LM: Study design, data analysis, data interpretation, and manuscript preparation. BE: Data analysis, data interpretation, and manuscript preparation. BS: Study design, data interpretation, and manuscript preparation. WS: Study design, data interpretation, and manuscript preparation. SH: Data interpretation and manuscript preparation. LP: Statistical analysis, data interpretation, and manuscript preparation. ED: Study conceptualization/design; data interpretation, and manuscript preparation.

All authors read and approved the final manuscript.

\section{Ethics approval and consent to participate}

Data for this study were collected with approval from the RAND Corporation's Institutional Review Board in Santa Monica, CA, the Human Subjects Protection Committee. We obtained permission from the 3 clinics in Pittsburgh and the clinic in Los Angeles and then they deferred ethics approval and consent to the RAND IRB. For interested adolescents, we obtained parental consent and assent (if under 18) or consent if 18.

\section{Consent for publication}

Not applicable.

Competing interests

The authors declare that they have no competing interests. 


\section{Publisher's Note}

Springer Nature remains neutral with regard to jurisdictional claims in published maps and institutional affiliations.

\section{Author details}

'RAND Corporation, 1776 Main Street, Santa Monica, CA 90407-2138, USA. 2VA HSR\&D Center for the Study of Healthcare Innovation, Implementation, and Policy, California, Los Angeles, USA. ${ }^{3}$ RAND Corporation, Pittsburgh, PA, USA.

Received: 12 April 2017 Accepted: 8 December 2017 Published online: 09 January 2018

\section{References}

1. Johnston LD, O'Malley PM, Miech RA, Bachman JG, Schulenberg JE. Monitoring the future national survey results on drug use, 1975-2015: overview, key findings on adolescent drug use. Ann Arbor: Institute for Social Research, The University of Michigan; 2016.

2. Adams WL. The effects of alcohol on medical illnesses and medication interactions. In: Gurnack AM, Atkinson R, Osgood NJ, editors. Treating alcohol and drug abuse in the elderly. New York: Springer Publishing Co; 2002. p. 32-49.

3. Eaton DK, Davis KS, Barrios L, Brener ND, Noonan RK. Associations of dating violence victimization with lifetime participation, co-occurrence, and early initiation of risk behaviors among U.S. high school students. J Interpers Violence. 2007:22:585-602.

4. aminer $Y$ and Bukstein OG. Adolescent substance abuse: psychiatric comorbidity and high-risk behaviors: Taylor \& Francis; 2008.

5. Martins SS, Alexandre PK. The association of ecstasy use and academic achievement among adolescents in two U.S. national surveys. Addict Behav. 2009;34:9-16.

6. Patton GC, Coffey C, Carlin JB, Degenhardt L, Lynskey M, Hall W. Cannabis use and mental health in young people: cohort study. Br Med J. 2002;325:1195-8.

7. Shrier LA, Harris SK, Kurland M, Knight JR. Substance use problems and associated psychiatric symptoms among adolescents in primary care. Pediatrics. 2003:111:e699-705.

8. Tripodi SJ, Springer DW, Corcoran K. Determinants of substance abuse among incarcerated adolescents: implications for brief treatment and crisis intervention. Brief Treatment and Crisis Intervention. 2007;7:34

9. McCambridge J, McAlaney J, Rowe R. Adult consequences of late adolescent alcohol consumption: a systematic review of cohort studies. PLoS Med. 2011;8

10. Centers for Disease Control and Prevention. The Cost of Excessive Alcohol Use: A Drain on the U.S. Economy. CDC 24/7: Saving Lives, Protecting People: Department of Health and Human Services; 2016.

11. National Drug Intelligence Center. The economic impact of illicit drug use on American society. https://www.justice.gov/archive/ndic/pubs44/44731/ 44731p.pdf (2011). Accessed.

12. Bloom B, Cohen RA. Summary health statistics for U.S. children: National Health Interview Survey, 2006. Vital Health Stat 10. 2007:1-79.

13. Johnson SB, Millstein SG. Prevention opportunities in health care settings. Am Psychol. 2003:58:475-81.

14. Newacheck PW, Brindis CD, Cart CU, Marchi K, Irwin CE. Adolescent health insurance coverage: recent changes and access to care. Pediatrics. 1999;104:195-202.

15. Ozer EM, Adams SH, Orrell-Valente JK, Wibbelsman CJ, Lustig JL, Millstein SG, et al. Does delivering preventive Services in Primary Care Reduce Adolescent Risky Behavior? J Adolesc Health. 2011:49:476-82.

16. U.S. Preventive Services Task Force. Alcohol Misuse screening and behavioral counseling interventions in primary care. www.uspreventiveservicestaskforce. org/uspstf/uspsdrin.htm. 2012. Accessed 1 May 2016.

17. American Academy of Pediatrics Committee on Substance Abuse. Policy statement-alcohol use by youth and adolescents: a pediatric concern. Pediatrics. 2010;125:1078-87.

18. NIAAA. Alcohol screening and brief intervention for youth: a practioners guide. NIH publication no. 11-7805. Rockville, MD: NIAAA, DHHS and AAP; 2011.

19. Hingson RW, Heeren T, Edwards EM, Saitz R. Young adults at risk for excess alcohol consumption are often not asked or counseled about drinking alcohol. J Gen Intern Med. 2012;27:179-84.
20. Hingson RW, Zha W, lannotti RJ, Simons-Morton B. Physician advice to adolescents about drinking and other health behaviors. Pediatrics. 2013; 131:249-57

21. Klein DJ, Allan MJ, Elster AB, Stevens D, Cox C, Hedberg VA, et al. Improving adolescent preventive care in community health centers. Pediatrics. 2001; 107:318-27.

22. Van Hook S, Harris SK, Brooks T, Carey P, Kossack R, Kulig J, et al. The "six T's": barriers to screening teens for substance abuse in primary care. J Adolesc Health. 2007:40:456-61.

23. Ozer EM, Adams SH, Gardner LR, Mailloux DE, Wibbelsman CJ, Irwin CE. Provider self-efficacy and the screening of adolescents for risky health behaviors. J Adolesc Health. 2004;35:101-7.

24. Sterling S, Kline-Simon AH, Wibbelsman C, Wong A, Weisner C. Screening for adolescent alcohol and drug use in pediatric health-care settings: predictors and implications for practice and policy. Addict Sci Clin Pract. $2012 ; 7: 13$

25. Marcell AV, Halpern-Felsher B, Coriell M, Millstein SG. Physicians' attitudes and beliefs concerning alcohol abuse prevention in adolescents. Am J Prev Med. 2002:22:49-55.

26. Center for Mental Health Services. Mental Health Care for Youth: A National Assessment, Annual/Final Progress Report, editors. Vol. January-December 2001. Rockville, MD: Substance Use and Mental Health Services Administration; 2001.

27. SAMHSA. Results from the 2011 National Survey on drug use and health: summary of national findings. NSDUH series $\mathrm{H}-44$, HHS publication no. (SMA) 12-4713. Rockville, MD: Substance Abuse and Mental Health Services Administration; 2012

28. Turner WC, Muck RD, Muck RJ, Stephens RL, Sukumar B. Co-occurring disorders in the adolescent mental health and substance abuse treatment systems. J Psychoactive Drugs. 2004;36:455-62.

29. Burnett-Zeigler I, Walton MA, Ilgen M, Barry KL, Chermack ST, Zucker RA, et al. Prevalence and correlates of mental health problems and treatment among adolescents seen in primary care. J Adolesc Health. 2012;50:559-64.

30. D'Amico EJ, Paddock SM, Burnam A, Kung FY. Identification of and guidance for problem drinking by general medical providers: results from a national survey. Med Care. 2005:43:229-36.

31. Sturm R, Gresenz C, Sherbourne C, Minnium K, Klap R, Bhattacharya J, et al. The design of healthcare for communities: a study of health care delivery for alcohol, drug abuse, and mental health conditions. Inquiry. 1999;36:221-33.

32. Winters KC. Development of an adolescent alcohol and other drug abuse screening scale: Personal Experiences Screening Questionnaire. Addict Behav. 1992;17:479-90.

33. Berwick DM, Murphy JM, Goldman PA, Ware JE Jr, Barsky AJ, Weinstein MC. Performance of a five-item mental health screening test. Med Care. 1991:29:169-76.

34. Gelman A and Hill J. Data analysis using regression and multilevel/ hierarchical models: Cambridge University press; 2006.

35. Rubin DB, Little RJA. Statistical analysis with missing data. Hoboken, NJ: J Wiley \& Sons; 2002.

36. Brener ND, Billy JO, Grady WR. Assessment of factors affecting the validity of self-reported health-risk behavior among adolescents: evidence from the scientific literature. J Adolesc Health. 2003;33:436-57.

37. Eisenhower D, Mathiowetz NA, Morganstein D. Recall error: sources and bias reduction techniques. In: Biemer PP, Groves RM, Lyberg LE, et al., editors. Measurement errors in surveys. New York: John Wiley \& Sons; 1991. p. 127-44.

38. DeMaio T. Social desirability and survey measurement: a review. In: Turner CF, Martin E, editors. Surveying social phenomena. New York, NY: Russell Sage Foundation; 1984. p. 257-82.

39. Poulin C, MacNeil P, Mitic W. The validity of a province-wide student drug use survey: lessons in design. Can J Public Health. 1993;84:259-64.

40. Johnston LD, O'Malley PM, Bachman JG, Schulenberg JE. Monitoring the future national survey results on drug use, 1975-2012. Volume I: secondary school students. Ann Arbor, Michigan: Institute for Social Research, The University of Michigan; 2013.

41. Patnode CD, O'Connor E, Rowland M, Burda BU, Perdue LA, Whitlock EP. Primary care behavioral interventions to prevent or reduce illicit drug use and nonmedical pharmaceutical use in children and adolescents: a systematic evidence review for the US preventive services task force. Ann Intern Med. 2014;160:612-U161.

42. Yarnall KS, Pollak KL, Ostbye $T$, Krause KM, Michener IL. Primary care: is there enough time for prevention? Am J Public Health. 2003;93:635-41. 
43. Earls MF, Hay SS. Setting the stage for success: implementation of developmental and behavioral screening and surveillance in primary care practice - the North Carolina assuring better child health and development (ABCD) project. Pediatrics. 2006;118:E183-8.

44. Saitz R, Cheng DM, Allensworth-Davies D, Winter MR, Smith PC. The ability of single screening questions for unhealthy alcohol and other drug use to identify substance dependence in primary care. Journal of studies on alcohol and drugs. 2014;75:153-7.

45. Smith PC, Schmidt SM, Allensworth-Davies D, Saitz RA. Single-question screening test for drug use in primary care. Arch Intern Med. 2010;170 1155-60.

46. Smith PC, Schmidt SM, Allensworth-Davies D, Saitz R. Primary care validation of a single-question alcohol screening test. J Gen Intern Med. 2009;24:783-8.

47. McCormick KA, Cochran NE, Back AL, Merrill JO, Williams EC, Bradley KA. How primary care providers talk to patients about alcohol: a qualitative study. J Gen Intern Med. 2006;21:966-72.

48. Stockwell T, Donath S, Cooper-Stanbury M, Chikritzhs T, Catalano P, Mateo C. Under-reporting of alcohol consumption in household surveys: a comparison of quantity-frequency, graduated-frequency and recent recall. Addiction. 2004;99:1024-33.

49. McNeely J, Cleland CM, Strauss SM, Palamar JJ, Rotrosen J, Saitz R. Validation of self-administered single-item screening questions (SISQs) for unhealthy alcohol and drug use in primary care patients. J Gen Intern Med. 2015;30:1757-64.

50. Buckelew SM, Adams SH, Irwin CE Jr, Gee S, Ozer EM. Increasing clinician self-efficacy for screening and counseling adolescents for risky health behaviors: results of an intervention. J Adolesc Health. 2008;43:198-200.

51. Ozer EM, Adams SH, Lustig JL, Gee S, Garber AK, Gardner LR, et al. Increasing the screening and counseling of adolescents for risky health behaviors: a primary care intervention. Pediatrics. 2005;115:960-8.

52. D'Amico EJ, Miles JN, Stern SA, Meredith LS. Brief motivational interviewing for teens at risk of substance use consequences: a randomized pilot study in a primary care clinic. J Subst Abus Treat. 2008;35:53-61.

53. Ambresin AE, Otjes CP, Patton GC, Sawyer SM, Thuraisingam S, English DR, et al. Training general practitioners to detect probable mental disorders in young people during health risk screening. J Adolesc Health. 2017;

54. Ozechowski TJ, Becker SJ, Hogue A. SBIRT-A: adapting SBIRT to maximize developmental fit for adolescents in primary care. J Subst Abus Treat. 2016:62:28-37.

\section{Submit your next manuscript to BioMed Central and we will help you at every step:}

- We accept pre-submission inquiries

- Our selector tool helps you to find the most relevant journal

- We provide round the clock customer support

- Convenient online submission

- Thorough peer review

- Inclusion in PubMed and all major indexing services

- Maximum visibility for your research

Submit your manuscript at www.biomedcentral.com/submit 